\title{
Scurvy and the enhancement of the senses
}

$\mathrm{T}$ he empiricism behind the new science of the 17th century was not a homogeneous doctrine. Although everyone agreed that observation was a surer route to knowledge than theory, there was no consensus about the relation of impressions the sight or feel of an object - to ideas. John Locke, for instance, was sure that "there is nothing like our ideas in the bodies themselves" and that even our impressions of colours and smells are illusions. ${ }^{1}$ Things in the world triggered certain agitations in the nerves that sent signals to the brain, where they were stored as signs, not images. David Hume disagreed. He said, "That idea of red, which we form in the dark, and that impression, which strikes our eyes in the sun-shine, differ only in degree, not in nature." 2

The implications of this sort of debate for the new Royal Society were profound. On the one hand were those who believed our senses, though not perfect, gave the mind sufficient ideas to identify the true nature of things; on the other hand were those who thought the senses needed help, for if the image or print of a thing was distorted, how could the idea of it be accurate?

Scientists such as Robert Boyle and Robert Hooke set to work to construct devices designed to make sense impressions keener. Yet there was no unanimity about exactly what a machine like a microscope did: whether it cleared away the doors of perception and rendered the arrival of an impression pure, full and immediate, or whether it elbowed its way into the business of cognition, supplying the eye, ear or nose with second-hand information.

When people laughed at this desire for finer sense perception, they produced hypotheses of ridiculous susceptibilities: ears deafened by the fall of a leaf; eyes blistering in the sunlight; a nose so sensitive its owner

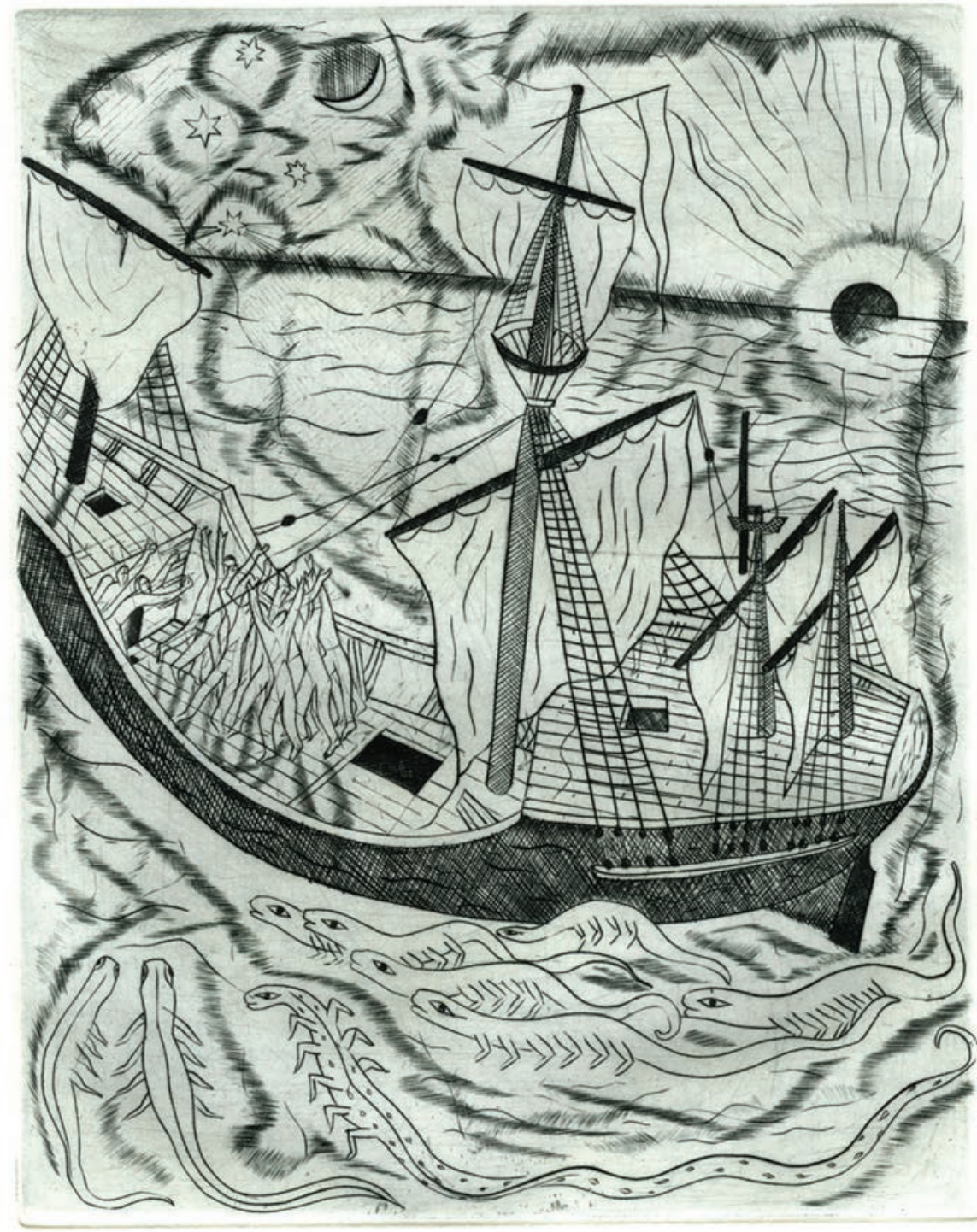

David Jones, The Death Fires, copper engraving from The Rime of the Ancient Mariner (Bristol, 1929). @Trustees of the Estate of David Jones, by kind permission of the trustees.

could die of the smell of a rose. But these conjectures were not entirely improbable, for the laboratories most copiously stored with equipment for carrying the senses into the remote or minute spheres of matter were ships. And the farther those laboratories carried navigators and scientists into places they had never been before, the more likely they were to succumb to a nutritional disease called scurvy. Scurvy mimicked the effects of these prosthetic devices by imparting a morbid sensitivity to the nerves.

When the French naturalist Jacques-Henri Bernardin de SaintPierre arrived in Mauritius, his eyes, nose and palate were deeply offended by everything they met: the trees smelled of shit, the flesh of pigeons 
nearly poisoned him, and the vegetation was superlatively ugly and coloured a hideous green. Herman Melville was once aboard a ship enveloped in the aroma of flowering shrubs drifting from the shore when he heard a sailor shrieking in pain at the smell. The same extravagant reactions to natural phenomena are represented in the great fictions of voyaging: Gulliver's disgust at the filthiness of the Yahoos and the Ancient Mariner's horrified reaction to the texture of the sea snakes ("O Christ!/That ever this should be!/Yea, slimy things did crawl with legs/Upon the slimy sea"). ${ }^{3}$ All of these individuals exhibit a sensory overload caused by scurvy.

Thomas Trotter, a naval physician, offered the public extensive accounts of the unpleasant sensory disturbances of scorbutic seamen: dilated pupils, double vision, tinnitus, raw skin, mouths filled with the excrescences of rotten gums and noses pathologically susceptible to odours. ${ }^{4}$ But he also witnessed the pathos and even the triumph of morbidly enlarged sensations, for scorbutic sailors had marvellously vivid reactions to images of what their bodies desired.

The cravings of appetite not only amuse their waking hours with thoughts on green fields, and streams of pure water; but in their dreams they are tantalized by the favourite idea; and on waking the mortifying disappointment is expressed with the utmost regret, with groans, and weeping, altogether childish. ${ }^{5}$

But then when the desired thing actually materializes, what a remarkable shift from the misery of want to ecstasies of satisfaction:

The patient in the inveterate stage of the disease seems to gather strength even from the sight of fruit: the spirits are exhilarated by the taste itself, and the juice is swallowed, with emotions of the most voluptuous luxury. ${ }^{6}$

Coleridge's parched Mariner wakes from a dream of drinking to find his thirst being quenched by the rain falling on his bare skin: "Sure I had drunken in my dreams,/And still my body drank." 7 John Mitchel, an Irish political prisoner en route for Tasma- nia aboard a scorbutic transport, wished never to forget the "brutal rapture" with which he devoured six oranges when the ship landed in Pernambuco. Sometimes the very thing that at first seemed so disgusting and repugnant turns into the opposite, or vice versa. Anders Sparrman, one of the naturalists on James Cook's second voyage, landed at Dusky Bay in New Zealand with scurvy and, badly in need of fresh food, went duck shooting:

The blood from these warm birds which were dying in my hands, running over my fingers, excited me to a degree I had never previously experienced. ... This filled me with amazement, but the next moment I felt frightened. ${ }^{8}$

Lack of vitamin $\mathrm{C}$ plays havoc with the cranial nerves because free radicals, the waste product of activity in the neuronal pathways of the brain, are no longer cleared away by antioxidants. This results in spasmodic bursts of nervous energy in the synapses. It was Robert Boyle who suggested that there were some diseases capable of causing the same magnification of sensory inputs as the prosthetic devices, the microscopes engineered by his colleague and collaborator, Hooke. There is the man who, having recovered from the plague, could smell an infected person before any tokens of the infection were visible; another who was able, after a severe inflammation of his eyes, to see colours in the dark; and another, a physician, who fell sick of a fever and discovered afterward he could overhear whispered speech at a great distance. ${ }^{9}$ The organs of the living engine of the body, having been pierced by infection, collaborate to produce a sensitivity that is not merely passive, but an emittent faculty bent upon heightened apprehensions of real objects and events. Boyle never mentions scurvy, which, though not an infectious malady, deserved a place among his examples.

A curious junction in the trajectories of diseases of discovery and pneumatic experiment was reached when Humphrey Davy decided in 1799 to test the claim by American chemist Samuel Mitchill that nitrous oxide was responsible for all contagious diseases, among them scurvy. Davy subjected the gas to a series of tests and found no trace of the alleged mephitic agency. However, he did discover that his reactions after inhaling it were those of someone whose sensations had been preternaturally enlarged:

I imagined that I had increased sensibility of touch: my fingers were pained by anything rough. ... My visible impressions were dazzling and apparently magnified ... when I have breathed it amidst noise, the sense of hearing has been painfully affected even by moderate intensity of sound. ${ }^{10}$

Mitchill had been wrong about contagion, but Davy's experiment revealed a link between scurvy, abnormal functioning of the senses and experimental prosthetics that deserves attention. You could die of a rose in aromatic pain, and what kind of knowledge would that impart?

\section{Jonathan Lamb BA DPhil}

Andrew W. Mellon Professor of the

Humanities, Department of English, Vanderbilt University, Nashville, Tenn.

Author of The Things Things Say (2011) and Scurvy, the Disease of Discovery (2016)

\section{References}

1. Locke J. Book II, chapter viii, paragraph 15. An essay concerning human understanding. In: Nidditch PH, editor. Oxford: Clarendon Press; 1979.

2. Hume D. A treatise of human nature. In: SelbyBigge LA, Nidditch PH, editors. 2nd ed. Oxford: Oxford University Press; 1978.

3. The rime of the ancient mariner. Part II, stanza 11. In: William Keach, editor. The complete poems of Samuel Taylor Coleridge. London (UK): Penguin, 2004.

4. Trotter T. Medicina nautica: an essay on the diseases of seamen. 2nd ed. 3 Vols. London: Longman; 1804;3:362.

5. Trotter T. Observations on the scurvy. London: T. Longman; 1792:44

6. Trotter T. Observations on the scurvy. London: T. Longman; 1792:141-2.

7. The rime of the ancient mariner. Part $\mathrm{V}$, stanza 2 In: William Keach, editor. The complete poems of Samuel Taylor Coleridge. London (UK): Penguin, 2004.

8. Sparrman A. A voyage round the world with Captain James Cook in HMS Resolution. In: Rutter O, editor. London: Golden Cockerel Press; 1944:60.

9. Boyle R. "Of the determinate nature of effluviums." In: Hunter M, Davis EB, editors. The works of Robert Boyle. 14 vols. London: Pickering and Chatto; 1999; 7:282.

10. Davy H. Researches, chemical and philosophical, chiefly concerning nitrous oxide. London: J. Johnson; 1800:464,487,491.

This article has been peer reviewed.

CMAJ 2016. DOI:10.1503/cmaj.160199 